\title{
Examination of 'Pause' in Pinter's The Homecoming and Baker's Circle Mirror Transformation
}

\author{
Rua'a Tariq Jawad \\ College of Education for Women, University of Baghdad, Iraq \\ Nawal Fadhil Abbas, PhD \\ College of Education for Women, University of Baghdad, Iraq \\ nawal_fa71@yahoo.com \\ Maysoon Taher Muhi, PhD \\ College of Education for Women, University of Baghdad, Iraq
}

DOI: https://doi.org/10.36892/ijlls.v2i1.218

\begin{tabular}{|c|c|}
\hline Received: & Abstract \\
\hline $01 / 01 / 2020$ & Pauses as pragmatic markers are considered as important devices that help \\
\hline $\begin{array}{l}\text { Accepted: } \\
20 / 03 / 2020\end{array}$ & $\begin{array}{l}\text { readers to gain a better and deeper understanding of certain texts as well as } \\
\text { speech, promoting effectively language communication. For their } \\
\text { communicative function essentials, they can help both readers and hearers. } \\
\text { Their occurrence in speech has a value that tends to be quite understandable. }\end{array}$ \\
\hline $\begin{array}{l}\text { Keywords: } \\
\text { Pauses, } \\
\text { filled pauses, } \\
\text { silent pauses, } \\
\text { drama texts, } \\
\text { multifunctional use. }\end{array}$ & $\begin{array}{l}\text { In this regard, the present study aims to examine the forms and functions of } \\
\text { pauses in literary texts, more specifically, in selected extracts from two plays, } \\
\text { namely, Pinter's The Homecoming and Baker's Circle Mirror Transformation } \\
\text { and to compare how the two writers use pauses in these two dramas. To do so, } \\
\text { the sequential production approach of turn introduced by Sacks, Schegloff and } \\
\text { Jefferson (1974) has been used, in addition to the related pause multifunctional } \\
\text { use contributions. The findings of the present study show that pauses are not } \\
\text { arbitrarily used in speech, they are found to serve certain functions depending } \\
\text { on the context where they occur. Pauses, whether silent or filled, have certain } \\
\text { references. They are not meaningless. Pauses can shed enough light on the } \\
\text { inner side of characters without even saying a word. Upon examining the } \\
\text { selected extract from each play, it is noticed from the comparison that the two } \\
\text { dramatists employ pauses frequently. Pauses are used by the two writers to be } \\
\text { informative and that is why they should be studied thoroughly for the addition } \\
\text { they give to interpretation and understanding. . }\end{array}$ \\
\hline
\end{tabular}

\section{INTRODUCTION}

Pauses or as they are called "disfluencies" are considered as markers of spontaneous speech (Erard, 2004). The study of pauses has its roots in the 1950s (Maclay \& Osgood, 1959). Maclay and Osgood's study deals with role of pauses. Goldman-Eisler (1951), on the other hand, has studied pauses from a psycholinguistic perspective and has shown that there is a relation between "pause and lexical choice". In the early 1980s, a new approach appeared to highlight the relation between emphatic tools and pauses and the connection between pauses and pragmatics as well (Pribram, 1980). Brown and Yule (1983) emphasize the multifunctional use of pauses.

The study of pauses began in the mid-twentieth century by Maclay and Osgood and Goldman-Eisler. Many researchers have aimed to clarify the relationship between pauses and hesitation and particular linguistic processes like syntactic processing, discourse planning or lexical access. There is evidence to support these possibilities in various studies. Besides, there 
is an agreement upon the fact that pauses are used by the speaker to make a processing decision in case of making errors or cognitive load (Clark \& Wasow, 1998). Many psycholinguists consider a pause as an indication of mental processes that cause the production of speech. They state that when people are faced with a problem in searching for certain words that fit or which are suitable for the utterance, they tend to produce it (Swerts, 1998).

O'Brein (2006) mentions that pauses may show cognitive processes. It has been stated that filled pauses occur for a cognitive load and sometimes for interpersonal factors such as trying to have more time before answering a certain question or even for repairing an utterance (Nicholson, Eberhard \& Schuetz, 2010). Pauses have been studied from different points of view by scholars from different specialties such as anthropologists, psycholinguists and sociolinguists. Moreover, many scholars have studied this phenomenon in relation to many social variables such as age, class and gender (Stenström, 2011). Many studies have shown that pauses fall into two types: silent pauses and filled pauses (Santos \& Pablo, 2016).

Pauses have been extensively studied in English and other languages such as Japanese, Chinese and German. Although pauses are very obvious in spoken discourse, they can be studied in written discourse as well. For example, many playwrights use certain words and interjections such as ah and other markers of pauses like triples, dashes and ellipsis to show that there is a pause. Dramatists also use phrases such as "short pause" and "long pause" (O'Connell \& Kowal, 2004).

\section{LITERATURE REVIEW}

\section{1 What is a pause?}

Pauses are considered as a very necessary part of speech. Different studies have mentioned that the percentage of pause duration ranges from $20 \%$ to $50 \%$ of the total duration of speech in real speech and from $30 \%$ to $46 \%$ in spontaneous speech. Pauses are either silent or filled. Fillers are used to fill pauses, express hesitancy in addition to performing many other functions. They can be non-lexical items. Examples of such a kind of fillers in the English language are um and uh. On the other hand, there is another kind of fillers, for example; well, like, you know, which are examples of lexical items (Yuan, Xu \& Liberman, 2016). From a linguistic point of view, pauses as markers of speech disfluencies. Lately, pauses are presented as being a valuable aspect in speech and linguists have become interested in their various functions (Tellier, 2013).

Fillers are considered as discourse markers that language users manipulate when they think of what they like to say prior to speech production. They are probably used in oral interaction to fill pauses (Erten, 2014). These fillers give the speaker time to think and choose the appropriate words during conversations (Richards \& Schmidt, 2010). Pauses can be expressed by means of fillers. Fillers are one of the characteristics which very often occur in speech. Pauses constitute a phenomenon to be seen in the production of speech (Santos \& Pablo, 2016).

To Wang and Li a "pause means a break in speaking or a moment of silence" (2015, p. 125). Pauses are used to "refer to as silence, hesitation and junctures" (Cecot, 2001, p. 65). Furthermore, pauses are considered as a type of discourse markers. They have different indications. For example, um is used to indicate an upcoming delay or it can suggest that the person talking is lying, also it helps in conversation management (Fox Tree, 2010). Thus, they have communicative functions in the context in which they are used. They have many different communicative functions that are determined with reference to their context of use. From a descriptive perspective, two classifications of pauses can be found. The first is physical and 
linguistic classification while the second is psychological and psycholinguistic classification (Zellner, 1994).

Pauses are not only used according to the way users intend them to mean. Some studies have been done to show how these pauses are interpreted by people themselves and how they use them. In speech production, long pauses are exceedingly important for two reasons. Firstly, they provide the speaker with enough time to prepare the next information. Second, they are of great importance in speech perception as they aid the hearer to digest the input cognitively (Oliveria, 2002).

Tissi (2000) further emphasizes the communicative value of disfluencies in addition to the skill in using them for knowing what the speaker may mean by a certain utterance and to reach a certain interpretation. Additionally, Tissi divides pauses into two types which are: silent pauses and disfluencies. Under disfluencies heading, there are filled pauses that are subdivided into consonant, vowel lengthening and vocalized hesitation. The other division of disfluencies is interruptions which are subdivided into false starts, repeats and restructuring.

In view of the fact that speech is basically an individual activity, the occurrence of pauses mostly depends on the specific speaker. The situational context must also be taken into consideration. It is critical because it affects the speaker's expressive capacities; for example, performing a difficult task in communication, being under stress while speaking, speaking under emotional pressure and so on (Zellner, 1994).

\section{2 Types of pauses}

It is pinpointed that individuals who are slow in speaking usually utilize more pauses than individuals who are quick in speaking. It is exciting to know the fact that throughout speaking up to $50 \%$ of speech time may be composed of pauses (Richards \& Schmidt, 2010). As such, pauses help listeners facilitate the process of understanding the speaker's message (Tissi, 2000).

\section{2. 1 Silent pauses}

Silent or unfilled pauses are breaks in the speech production and they differ in length in that they are short or long (Crystal, 2008). Punctuation is considered as a way of expressing pauses in writing. In speech, pauses have relations with tone unit boundaries. These pauses are important for both the speakers and the listeners, i.e., they help the speakers to organize what they like to say, and give time to the hearers to think about what is said. They perform the action of making the boundaries of words in addition to being interactional devices and they mark emphasis (Stenström, 2011).

Cecot (2001) shows that pauses and fluency interruptions are considered as features of natural speech which are categorized as the following:

a. Silent pauses or initial delay "for the interpreter, correspond to the décalage with the source text" (p. 69).

b. Silent pauses which occur within utterances or juncture pause: pauses of this type occur at grammatical junctures. They are valuable for both the speaker and the hearer simultaneously. As speakers produce an utterance, they pause in order to take a breath. This process happens at the same time with the grammatical juncture which helps the hearer in understanding the syntactic organization of the discourse.

c. Silent pauses, which occur within clauses, do not occur at grammatical junctures because of factors related to cognition and speech disorder or of sociolinguistic factors.

\subsection{Filled pauses}

A filled pause is defined as "a term used by linguists to refer to non-silent pause that is to say hesitation which has been filled by er, erm or some vocalization" (Crystal, 2008, p. 188). The way filled pauses are expressed is decided by the language. In each language, pauses are expressed differently (Stenström, 2011); for example, uh and um are used in American English, er and erm are used in British English, in Spanish the use of uh and um are noticed 
etc. (Weiling, Grieve \& Bouma, 2016). If the filled pause occurs in initial position, it is preferable to have silent pauses before and after it (Swerts, 1998).

According to Fox Tree (1995), pauses can be found in three different forms:

(1) An extended middle vowel; for example, "aa" or "oo".

(2) A nasal mumble only; for example, "mm".

(3) A middle vowel followed by nasal mumble; for example, "eem".

Filled pauses are different as far as length is concerned. Colon is a way of referring to long filled pauses, for example; e: r, e: rm (Stenström, 2011). According to Cecot (2001, p. 69), "Filled pauses is the occurrence of hesitation interjections." Krikke (2014) states that filled pauses are devices that the participants in a certain conversation use to take time to produce an utterance or to fill pauses. Most filled pauses in such languages as English and French are drawls, repetition of utterances, words, syllables, sounds and false starts (Bloodstein, 1981).

Zellner (1994) mentions that filled pauses tend to occur between words, for those speakers who do not have speech problems or speech disorder. Erard (2004) states that filled pauses are used to fill gaps in speech production and if they do not exist, there will be a silent pause. Filled pauses (occasionaly called fillers) entail the pronunciation of a certain sound throughout the delay. The sound may be akin to a real word or be a non-lexical form, for example; um and uh in English. Brennan and Williams (1995) illustrate that speakers are seen to have more knowledge in answering certain questions when their answers are accompanied by filled pauses as if s/he is trying to restore something from his/her memory. Using filled pauses is preferable to language learners as they help them to develop and improve their communicative competence (Rose, 1998).

Filled pauses, as the name suggests, are silent pauses filled with a certain noise or vocalization, i.e, which the speaker utters during speaking (Eriksson, 2012). Several linguists such as Schachter, Christenfeld, Ravina and Bilous (1991) think about filled pauses as being disfluencies and their existence is considered as a shortcoming in speech. The researchers of the present study disagree with this and side with Fox Tree (2010) who states that filled pauses generate fluency. It is more logical to consider them as devices that maintain the smoothness of communication during interaction, principally because it rarely happens that filled pauses divert the hearer' $s$ attention or disturb communication.

\section{3 Functions of pauses}

During the process of speech production, speakers manipulate fillers which are considered as discourse markers. Speakers tend to use fillers to fill the gaps when they are thinking about what to say. According to Clark and Fox Tree (2002), fillers play a communicative function in speaking. Furthermore, researchers state that fillers do not convey a main message, but a secondary one, that is to say, they are tools to facilitate understanding the meaning during communication but not the meaning itself.

Pauses have many functions. One of the main functions that pauses perform is expressing hesitancy. The existence of a pause is decided by a number of factors, including showing emphasis, anxiety, interrupting the speaker, intersubjectivity, having a breathe, availability, syntactic complexity and so on (Oliveria, 2002). Pauses normally exist at important points in the discourse. They have an influence upon the rhyme as well as intonation. It is noticed that pauses are an important part of interaction and have a communicative value. Silent and filled pauses are mechanical reactions to the problems of speech planning which increase as a result of the cognitive load needed for deception (which is one of the functions of pauses) (Benus, Enos, Hirschberg \& Shriberg, 2006). Speakers tend to use long pause and extra fillers preceding an answer which they lack confidence in or before providing an answer which is probably wrong. Speakers also tend to use long pauses with additional fillers when they truly know the answer, but incapable of retrieving it (Brennan \& Williams, 1995). Besides, 
pauses can be used to refer to the fact that there is an interruption in one's idea (Fuller, Masteller \& Talkington, 2017). Pauses can be used to achieve different functions as stated below:

\section{3. 1 Expressing hesitancy}

Following Stepanova (2007), one of the functions of pauses is reflecting hesitations. Speakers tend to use them when they are in a process of searching or selecting suitable words. When speakers are encountered with something, they are not sure about, they tend to hesitate and this hesitation can be expressed by means of pauses. The reason behind the relationship between pauses and hesitations is that expressing hesitancy is one of the functions of pauses (Ekland \& Wiren, 2010). In this line of thought, Marrouchi (2019, p. 116) has gone a step further to stress that pauses, by means of hesitations, are meant to "intensify the sense of restlessness, fear and death."

\section{3. 2 Interactional role}

Pauses have important roles during oral communication. They play an interactional role that they help a speaker in holding a turn in a conversation in addition to expressing thinking and mental states. Some researchers see filled pauses as being unwanted, needless and annoying to the listener, so that people try to learn how to avoid using them by taking special courses. The researchers of the present study side with those who admit the importance of using them (Tsiaras, Panagiotakis \& Stylianou, 2009).

\subsubsection{Demarcating function}

Another function of pauses in addition to expressing hesitations and the interactional function is that pauses have a demarcating function. In other words, silent pauses mark word boundaries. Pauses habitually serve to mark the borders between phrases, sentences and clauses, and sentence (Rose, 1998).There is a tendency for long pauses to be followed by filled pauses. Filled pauses not only mark word boundaries, but also they mark stages in the discourse (Labov \& Fanshel, 1977). They help in organizing the whole utterance. As a motor activity, the process of producing speech cannot be continuous, consequently using pauses as well as interruptions is essential (Zellner, 1994).

\section{3. 4 Physiological function}

Pauses occur as a result of the physiological necessity to continue breathing. "Physiologically predictable pauses coincide with the inspiration segment of respiration since phonation is related to respiratory activity" (Zellner, 1994, p. 21). In other words, pauses perform the function of giving the chance for the speaker to take a breath which is a physiological function (Cenoz, 1998).

\section{3.5 The affective and cognitive functions}

Due to these functions, speakers use pauses for the sake of smoothing the conversation. The purpose behind using them is to reflect anxiety, mental states, humility as well as hesitation, in addition to reflecting different thinking states, such as, looking for stored information or trying to find suitable words (Goto, Itou \& Hayamiza, 1999). They are used as devices to plan what the speaker wants to say and when he /she tries to find the suitable words (Maclay \& Osgood, 1959; Clark \& Fox Tree, 2002). Pauses constitute the outer demonstration of a number of the cognitive processes in speech production because pauses supply the speaker with additional time for planning and encoding the utterance. Hence, when the speaker produces a relatively complex utterance a speaker takes time to think before responding. In case speakers want to provide a response to a certain question instantly, they perhaps discontinue to take time to think talking again (Zellner, 1994).

\section{3. 6 The pragmatic function}

The pragmatic function is another function for pauses. They express that the speaker is not sure about what he/ she wants to say (Arnold, Fagnano \& Tanenhaus, 2003). Speakers may use pauses in order to declare less commitment concerning the produced utterance (Brennan \& Schober, 2001). Pauses are used when the speaker is not expected to know answers to general knowledge questions. They express uncertainty (Brennan \& Williams, 1995). 


\section{3. 7 Social cohesion}

Fillers such as ah, eh, you know etc. can be used to create a kind of membership in a certain group of people. They can bring the participants in a certain conversation closer to each other reducing the social distance between them (Mariano, 2002).

\section{3. 8 Request for confirmation}

Fillers can also be used by a participant in a certain conversation to demand agreement or confirmation. A speaker may use a certain filler as a request to the hearer to agree with what is said (Mariano, 2002).

\section{3.9 Signaling attention}

Fillers may be used to signal the attention and tentativeness of a listener. Sometimes a participant in a certain conversation prefers not to speak and uses a filler such as huh to occupy the whole turn showing his/ her tentativeness regarding what is said (Mariano, 2002). 2. 3. 10 Request for explanation

Another function of fillers is using them by the speaker to demand an explanation and clarification of what is said by a certain participant which is not clearly understood by the others and needs to be clarified (Mariano, 2002).

\subsection{Agreement of the listener}

The participant in a certain conversation can use fillers to reflect that s/he agrees with or confirms what is said by the speaker (Mariano, 2002).

\section{3. 12 Reception and acquisition of consciousness}

Fillers can be used as a reaction when the hearer is shocked regarding what is said or to express disapproval, surprise, limited understanding etc. (Mariano, 2002).

\section{METHODOLOGY}

The procedure followed in the present study is intended to enhance the reader's understanding of the selected texts. It includes particular steps; namely, specifying pauses utterances within the selected extracts and investigating their functions. The sequential production approach of Sacks et al. (1974) will be followed in combination with other contributions that show the multifunctional uses of pauses to come up with an eclectic model in order to clarify the functions of pauses. Pragmatically speaking, pauses are used as a device to keep the turn and to help the speakers to formulate and choose suitable words when they face a problem in conveying their ideas (Maclay \& Osgood, 1959).

The sequential production approach implies, according to Sacks et al. (1974), that each speaker takes part in a conversation at a specific time. It is clear that in any conversation turns to occur serially. What is special about the sequential production approach is that it takes into consideration verbal and non-verbal aspects, i.e., sounds and body movement as well. Hence, the researchers of the present study will follow this approach in combination with the functions stated by different scholars, for example, the pragmatic function, the cognitive function, expressing hesitancy and holding turn to come up with an eclectic model that serves the purpose of this study.

\section{RESULTS AND DISCUSSION}

The researchers will analyze two extracts from each of the two plays for the sake of investigating the different functions that pauses achieved in each text.

\section{1 The first selected extract from Pinter's The Homecoming}


(Act two, pp. 66-67)

(1) JOEY: I didn't say she was a tease.

(2) LENNY: Are you joking? It sounds like a tease to me, doesn't it to you, Ted?

(3) TEDDY: Perhaps he hasn't got the right touch.

(4) LENNY: Joey? Not the right touch? Don't be ridiculous. He's had more dolly than you've had cream cakes. He's irresistible. He's one of the few and far between. Tell him about the last bird you had, Joey.

Pause.

(5) JOEY: What bird?

(6) LENNY: The last bird! When we stopped the car...

(7) JOEY: Oh, that ... yes ... well, we were in Lenny's car one night last week...

(8) LENNY: The Alfa.

(9) JOEY: And er... bowling down the road...

(10) LENNY: Up near the Scrubs.

(11) JOEY: Yes, up over the Scrubs...

(12) LENNY: We were doing a little survey of North Paddington.

\section{1. 1 Contextualizing the extract}

In this extract, Lenny is asking Joey whether he wants to tell him that Ruth is a tease. Then, he moves to ask his brother Teddy whether Ruth has become a tease. Joey mentions that he does not mean that she is a tease. Lenny asks Joey to tell Teddy about the last bird he has in order to prove that Joey is irresistible.

\section{1. 2 Identifying pause items}

This extract is taken from act two. It contains ten pause items. Three characters are involved in this extract, namely, Lenny, Joey and Teddy. The following table shows pause items, their types, producers, receivers and functions.

Table 1. Pause items, types, producers, receivers and functions in the first extract

\begin{tabular}{|c|c|c|c|c|c|}
\hline No. & Pause item & Pause type & Producer & Receiver & Function \\
\hline 1. & $\ldots$ & Silent & Lenny & Joey & Processing \\
\hline 2. & Oh & Filled & Joey & Lenny & Change of situation \\
\hline 3. & $\ldots$ & Silent & Joey & Lenny & Processing \\
\hline 4. & $\ldots$ & Silent & Joey & Lenny & Processing \\
\hline 5. & Well & Filled & Joey & Lenny & Processing \\
\hline 6. & $\ldots$ & Silent & Joey & Lenny & Processing \\
\hline 7. & Er & Filled & Joey & Lenny & Turn holder \\
\hline 8. & $\ldots$ & Silent & Joey & Lenny & Processing \\
\hline 9. & $\ldots$ & Silent & Joey & Lenny & Processing \\
\hline 10. & $\ldots$ & Silent & Joey & Lenny & Processing \\
\hline
\end{tabular}

\section{1. 3 Investigating the functions of pause items}

In utterance (6), Lenny asks Joey to tell Teddy about his last bird. He uses a silent pause (...) at the end of the utterance in order to give the hearer (Joey) time to think about what is said and retrieves this event from his mind. Joey uses oh at the beginning of utterance (7), to indicate an upcoming change of the situation. In other words, Joey suddenly remembers information concerning the bird which is previously forgotten. Then, in the same utterance, he uses a silent pause twice to reflect the fact that he tries to retrieve something from his mind concerning the bird which is forgotten previously. Again in the same utterance, Joey uses well to refer to that he is in the process of consulting his thoughts about the forgotten information. 
Finally, at the end of utterance (7), he uses a silent pause too to reflect that he keeps remembering that event.

In utterance (8), Lenny tries to give Joey a hint in order to help him remember the event. In utterance (9), Joey uses "And" then he uses er to signal holding the turn and it is followed by a silent pause because he needs time to organize his ideas. At the end of the same utterance, Joey uses a silent pause (...) again because he keeps consulting his thoughts and trying to retrieve something from the mind. In utterance (10), Lenny again gives Joey a hint in order to help him to remember. In utterance (11), Joey repeats Lenny's utterance and uses a silent pause at the end to indicate that he is processing something in mind. It is obvious that most of the pauses items in this extract reflect processing since the extract revolves around Joey's remembering his last bird. In addition to processing, pauses perform other functions such as referring to an upcoming change of a situation and holding a turn.

\section{2. The second selected extract from Pinter's The Homecoming}

(Act two, p. 80-81)

(1) MAX: I'm not old, I suppose. She thinks I'm an old man.

\section{Pause.}

(To RUTH) You think I'm too old for you?

\section{Pause.}

Listen. You think you're just going to get that big slag all the time? You think you're just going to have him ... you're going to just have him all the time? You're going to have to work! You'll have to take them on, you understand?

\section{Pause.}

Does she realize that?

Pause.

Lenny, do you think she understand...

He begins to stammer.

What ... what ... what ... we're getting at? What ... we've got in mind? Do you think she's got it clear?

\section{Pause.}

I don't think she's got it clear.

Pause.

You understand what I mean? Listen, I've got a funny idea she'll do the dirty on us, you want to bet? She'll use us, she'll make use of us, I can tell you! I can smell it! You want a bet?

\section{Pause.}

She won't ... be adaptable!

\section{2. 1 Contextualizing the extract}

In this extract, Max addresses Ruth asking her if he does not appeal to her. Moreover, he asks her whether he is too old to her because she is in her early thirties while he is an old man in his seventies. He wonders whether the reason is his old age. He starts criticizing her and he asks Lenny whether she understands what he says. Max is a strange person as he agrees that his daughter in law works as a prostitute to bring money. There is a kind of contradiction in his personality that when he meets Ruth first he becomes angry because he thinks she is a prostitute and after that he himself supports the idea of working as a prostitute just to improve themselves financially. 


\section{2. 2 Identifying pause items}

This extract is taken from Act two. It contains eight pause items. Three characters are involved in this extract, namely, Max, Ruth and Lenny. The following table shows pause items, their types, producers, receivers and functions.

Table 2. Pause items, types, producers, receivers and functions in the second extract

\begin{tabular}{|c|c|c|c|c|c|}
\hline No. & Pause item & Pause type & Producer & Receiver & Function \\
\hline 1. & $\ldots$ & Silent & Max & Ruth & Hesitation \\
\hline 2. & $\ldots$ & Silent & Max & Lenny & Hesitation \\
\hline 3. & Repetition (what) & Filled & Max & Lenny & Hesitation \\
\hline 4. & $\ldots$ & Silent & Max & Lenny & Hesitation \\
\hline 5. & $\ldots$ & Silent & Max & Lenny & Hesitation \\
\hline 6. & $\ldots$ & Silent & Max & Lenny & Hesitation \\
\hline 7. & $\ldots$ & Silent & Max & Lenny & Processing \\
\hline
\end{tabular}

\section{2. 3 Investigating the functions of pause items}

The whole extract is uttered by Max as one long speech. It is noticed that he uses pauses frequently. First of all, he uses a silent pause when he says "Listen. You think you're just going to get that big slag all the time?, You think you are just going to have him ... you are going to just have him all the time? You're going to have to work! You'll have to take them on, you understand?" in order to express his hesitancy, uncertainty and confusion. Commenting on such an atmosphere, Marrouchi (2019, p. 112) has aptly remarked that:

Pinter presents his audience with an atmosphere that repeats in almost his twenty-nine mysterious plays. While fear ignites horror and anxiety in a Pinter play, interest tends to arouse as an element to guide the reader/ audience throughout the work. While the characters he introduces interact, their utterances seem to be devoid of meaning. While his dramatic action illogically proceeds, usually confusing the audience/ reader, the sense of menace increases to announce a tragic loss looming ahead; the very absurdity of our existence, the human being existence.

For a second time he uses a silent pause when he addresses Lenny by asking him "Lenny, do you think she understands ...", in order to reflect his hesitancy. Then, he uses three silent pauses within the same question and the repetition of the question "What... what... what... we're getting at? What... we've got in mind? Do you think she's got it clear?", to indicate that he is hesitant and does not know what to say since he talks about a sensitive issue the thing which makes him hesitant and confused.

For the last time, he uses a silent pause when he says "She won't... be adaptable!", in an attempt to process what he wants to say since he directs many questions so he needs to arrange his ideas. Max is the only character who speaks and directs questions, in this extract, who uses pauses frequently. This is due to the sensitive topic he talks about. So, he needs to have time because he is hesitant concerning what to say and he needs time for processing. He uses repetition once and silent pauses six times in a way that aids a conversation to go on easily. The functions of pauses in this extract are expressing hesitancy and processing.

\section{3 The third selected extract from Baker's Circle Mirror Transformation}


(Week one/ Scene four/ p. 18-19)

(1) SCHULTZ: (To Theresa.)

So you're a ... you like to hula hoop!

(2) THERESA: Um. The correct name is actually "hooping."

(3) SCHULTZ: Oh god. I'm sorry.

(4) THERESA: No, no. It's a common, um ... but "hula hooping" is actually, um ... it's misnaming.

(5) SCHULTZ: Ah.

(Schultz keeps starting at the hoop. James reenters and stands near the doorway, watching Schultz and Theresa).

(6) SCHULTZ: It's big.

(7) THERESA: The big ones are easier to use.

Wanna see?

\section{3. 1 Contextualizing the extract}

In this extract, Schultz has a conversation with Theresa. He begins the conversation by asking her if she likes hula hooping but she corrects him, saying that the correct name is hooping and hula hooping is just misnaming. Then, he discusses with her the big size of it and she replies that the big in size is easier to use. Schultz tries to talk to her to know her better and to be familiar with her as they are members of the same class.

\section{3. 2 Identifying pause items}

This extract is taken from Week one/ scene four. It contains eight pause items. Two characters are involved in this extract, namely, Schultz and Theresa. The following table pause items, their types, producers, receivers and functions.

Table 3. Pause items, types, producers, receivers and functions in the third extract

\begin{tabular}{|c|c|c|c|c|c|}
\hline No. & Pause item & Pause type & Producer & Receiver & Function \\
\hline 1. & $\ldots$ & Silent & Schultz & Theresa & Hesitation \\
\hline 2. & Um & Filled & Theresa & Schultz & $\begin{array}{c}\text { New information about to } \\
\text { come }\end{array}$ \\
\hline 3. & Oh & Filled & Schultz & Theresa & $\begin{array}{c}\text { Reaction to a surprising } \\
\text { information }\end{array}$ \\
\hline 4. & Um & Filled & Theresa & Schultz & Delay \\
\hline 5. & $\ldots$ & Silent & Theresa & Schultz & Processing \\
\hline 6. & Um & Filled & Theresa & Schultz & Processing \\
\hline 7. & $\ldots$ & Silent & Theresa & Schultz & Showing being surprised \\
\hline 8. & Ah & Filled & Schultz & Theresa & . \\
\hline
\end{tabular}

\section{3. 3 Investigating the functions of pause items}

In utterance (1), Schultz uses a silent pause (...) due to hesitancy and confusion in choosing suitable words. Theresa uses $\mathbf{U m}$ in utterance (2), to refer to the fact that there is new information about to come which is that the correct name of "hula hoop" is "hooping." Theresa tries to correct the name by providing such new information. In utterance (3), Schultz uses oh as a reaction to the surprising information regarding "hooping" that he thinks that the correct name is "hula hoop" but this is not true so he expresses his surprise by using oh. In utterance (4), Theresa uses um to indicate that a delay is about to come. $\mathbf{U m}$ is followed by a silent pause (...) to give her the time needed for processing. Within the same utterance again, she uses um also to indicate that there is an upcoming delay. $\mathbf{U m}$ here is also followed by a silent pause (...) to gain the time needed for organizing ideas. Theresa uses um as well as a silent pause twice 
in order to gain the time needed to make her idea clear and understandable. So using pauses facilitates this task to her.

Then in the utterance (5), Schultz uses "Ah" to occupy the whole turn in order to reflect the state of being surprised for hearing such information which he does not know before. In this extract Theresa and Schultz use different types of pauses. Silent pauses (...) are used three times to express hesitation and gain time needed for organizing ideas. Um is used three times to refer to an upcoming delay and to refer to the fact that there is new information about to come. Both oh and ah are used to perform the same function which reflects surprise.

\section{4 The fourth selected extract from Baker's Circle Mirror Transformation}

(Week one/ Scene one/ p. 11)

My name is Marty Kreisberg. Short for Martha, but they've been calling me Marty since I was born.

Ah ...

(He scratches his head, then grins.)

My husband is supposed to do this, ah, monologue about me but does not really know what to

(Marty is trying to signal something to him.)

Why can't I do that?

(He shakes his head.)

All right all right.

I'm 55 and I'm, ah ... I live in Shirley, Vermont. I'm co-executive director here at the Community Center and I also teach a bunch of classes ... ah... pottery, jewelry making, creative drama for youth ... I've been pushing for an adult creative drama class for a while and I'm ... I'm really glad they let me do it.

\section{4. 1 Contextualizing the extract}

In this extract, James a man of sixty years old, stands in the middle of the stage which represents a dance studio without windows. He faces the audience and addresses them. $\mathrm{He}$ acts as if he is Marty and tries to introduce her. He tries to present something about her. He talks in a way as if Marty was the one who talks. He starts mentioning Marty's name and her age moving to the place where she lives which is Vermont. Then, he mentions her job which is a co-executive director at the Community Center in addition to being a teacher of a bunch of classes, pottery and making jewelry.

\section{4. 2 Identifying pause items}

This extract is taken from week one/ scene one. It contains eleven pause items. One character is involved in this extract, namely, James. The following table shows pause items, their types, producers, receivers and functions.

Table 4. Pause items, types, producers, receivers and functions in the fourth extract

\begin{tabular}{|c|c|c|c|c|c|}
\hline No. & Pause item & Pause type & Producer & Receiver & Function \\
\hline 1. & $\mathrm{Ah}$ & Filled & James & Audience & Processing \\
\hline 2. & $\ldots$ & Silent & James & Audience & Processing \\
\hline 3. & - & Silent & James & Audience & Processing \\
\hline 4. & $\mathrm{Ah}$ & Filled & James & Audience & Processing \\
\hline 5. & $\ldots$ & Silent & James & Audience & Processing \\
\hline
\end{tabular}




\begin{tabular}{|c|c|c|c|c|c|}
\hline 6. & $\ldots$ & Silent & James & Audience & Processing \\
\hline 7. & Ah & Filled & James & Audience & Processing \\
\hline 8. & $\ldots$ & Silent & James & Audience & Processing \\
\hline 9. & $\ldots$ & Silent & James & Audience & $\begin{array}{c}\text { Physiological } \\
\text { function }\end{array}$ \\
\hline 10. & $\begin{array}{c}\text { Repetition } \\
(\mathrm{I} m)\end{array}$ & Filled & James & Audience & Processing \\
\hline 11. & $\ldots$ & Silent & James & Audience & Processing \\
\hline
\end{tabular}

\section{4. 3 Investigating the functions of pause items}

After mentioning Marty's name, James uses ah followed by a silent pause (...) then scratches his head to indicate that he is thinking so he uses ah and the silent pause in order to get enough time to process his ideas:

My name is Marty Kreisberg. Short for Martha, but they've been calling me Marty since I was born.

Ah...

(He scratches his head, then grins)

Then in the following utterance:

My husband is supposed to do this, ah, monologue about me but does not really know what to -

(Marty is trying to signal something to him.)

Ah is used as a filler to gain the required time for organizing ideas as it is supposed to introduce Marty to the audience who do not know her. It is noticed that there is a pause in a form of dash ( - silence) at the end of the utterance. The purpose behind using it is searching for suitable words to fill this gap, and that's why Marty tries to signal something to James in an attempt to push him to choose suitable words for his utterance since he is acting and she is the co-executive director.

James resumes talking as if he is Marty. He mentions her age, then it is noticed that he says "I'm 55 and I'm, ah ... I live in Shirley, Vermont. I'm the co-executive director here at the Community Center and I also teach a bunch of classes ... ah ... pottery, jewelry making, creative drama for youth ... I've been pushing for an adult creative drama class for a while and I'm ... I'm really glad they let me do it". In this utterance he uses ah followed a silent pause (...) then he continues "I live in Shirley, Vermont." Which indicates that he is in the process of searching for suitable words to address the audience. Then, he tries to list the things that Marty teaches since he lists things so he needs to formulate things in mind. The silent pause occurs after "for youth" and followed by "I've been pushing for adult creative drama class" in order to take a breath which is the physiological function of using pauses. Finally, he uses the repetition of "I'm" accompanied by a silent pause in order to consult his ideas concerning what to say. It is noticed that most of the items are used for processing ideas since he tries to act as if he were Marty and introduces her to the audience so he needs to organize what he wants to say.

\section{5 Comparison of the four selected extracts}

Each one of the two writers uses pauses in different ways and each pause has a certain function according to the context in which it occurs. In the extracts selected from Pinter's play, there are eighteen pause items which are: silent pauses (...), and filled pauses like oh, well, er and repetition. Each of these forms performs a certain function. The silent pauses are used for processing and retrieving something from mind. Oh is used to refer to an upcoming change of 
situation. Well is used for processing thoughts to remember forgotten information. Er is used to hold the turn while repetition is used to convey hesitation.

On the other hand, Baker manipulates pauses nineteen times throughout the two extracts. She uses silent pauses (...), and filled pauses like um, oh and $\mathbf{a h}$. Pauses used in the selected extracts serve various functions. Silent pauses and the filled pause ah are used for processing and expressing hesitancy. $\mathbf{U m}$ is used to refer to new information and to a coming delay. Oh is used as a reaction to a surprising information.

\section{CONCLUSION}

The researchers of the present study follow the sequential production approach of turn-taking together with the diverse functions of pauses which are presented by different scholars to analyze two extracts from each of the two plays. After conducting the analysis, the researchers have arrived at some results, including that pauses are not meaningless and not placed in the selected texts randomly, but they do have functions. They are valuable and play an important role in communication. Besides, the interpretation of pauses depends on the context in which they occur. They organize the discourse and enhance understanding as well.

Pauses help speakers in the speech production and aid listeners to understand via gaining time needed for understanding. Pauses do not exist haphazardly in the process of speech production. On the contrary, they play important roles and serve several functions the thing which makes them important and valuable in the process of speech production. As far as the selected extracts are concerned, it is obvious that both Pinter and Baker use pauses in a way that they reveal something regarding the characters and their states. The manipulation of pauses in the selected extracts has a value that pauses are as important as speech and readers should pay special attention to them that they make speech or texts more comprehensible. They organize the discourse and enhance understanding as well. In the extracts taken from Pinter's The Homecoming, it is noticed that the writer has used silent pauses, well, oh, repetition and er. In these extract, pauses serve different functions such processing ideas, referring to an upcoming change in a situation and as a device to hold the turn.

On the other hand, in the extracts taken from Baker's Circle Mirror Transformation, it is noticed that the writer has used silent pauses, um, oh and ah to serve several functions such as processing, expressing hesitancy, referring to new information and reacting to surprising information. On the whole and according to the analysis, it is obvious that Pinter and Baker use pauses frequently as they are as important as speech and tell the readers about the inner of the characters.

Acknowledgement: The researchers of the present study are indebted to the College of Education for Women, University of Baghdad, Al-Jadiriyya, for carrying out this study.

\section{REFERENCES}

Arnold, J. E. , Fagnano, M., \& Tanenhaus, M. K. (2003). Disfluencies signal theee, um, new information. Journal of Psycholinguistics Research,32(1), 25-36.

Benus, S., Enos, F., Hirschberg, J. \& Shriberg, E. (2006). Pauses and deceptive speech. Prosody Speech, 18, 2-5.

Bloodstein, O. (1981). Handbook on stuttering. Chicago: National Easter Seal Society for Crippled Children and Adults.

Brennan, S. \& Schober, M. E. (2001). How listeners compensate for disfluencies in spontaneous speech. Journal of Memory and Language, 44(2), 274-296. 
Brennan, S. \& Williams, W. (1995). The feeling of another's knowing: Prosody and filled pauses as cues to listeners about the metacognitive states of speakers. Journal of Memory and Language, 34, 383-398.

Brown, G. \& Yule, G. (1983). Discourse Analysis. Cambridge: Cambridge University Press.

Cecot, M. (2001). Pauses in simultaneous interpretation: A contrastive analysis of professional interpreters' performances. The Interpreters' Newsletter, 11, 63-85.

Cenoz, J. (1998). Pauses and communication strategies in second language Speech. Retrieved from http://files.eric.ed.gov/fulltext/ED426630.pdf

Clark, H. \& Fox Tree J. (2002). Using uh and um in spontaneous speaking. Cognition, 84 (1), 73-111.

Clark, H. \& Wasow, T. (1998). Repeating words in spontaneous speech. Cognitive Psychology, 37, 201-242.

Crystal, D. (2008). A dictionary of linguistics and phonetics (6th ed.). USA: Blackwell

Publishing.

Ekland, R. \& Wiren, M. (2010). Effect of open and directed prompts on filled pauses and utterance production. Proceedings of FONETIK. Dept. of Phonetics. Centre for and literature. Lund. Retrieved from http://www.divaportal.org/smash/get/diva2:539502/FULLTEXT01.pdf

Erard, M. (2004 January 3). Think tank; just like, er, words, not, um, throwdays. The New York Times. Retrieved from http://www.nytimes.com/2004/01/03/arts/think-tank-just-like-er-words- $\quad$ not-umthrowaways.html

Eriksson, S. (2012). Localization, frequency and functions of filled pauses: Five American politicians' use of er and erm in the talk show Harry King live. (Master thesis, Turku University, Turku). Retrieved from http://www.doria.fi/bitstream/handle/10024/88700/Eriksson2012gradu.pdf?sequence=1

Erten, S. (2014). Teaching fillers and students' filler usage: A study conducted at ESOGU preparation school. International Journal of Teaching and Education, 2 (3),67-79

Fox Tree, J. (1995). The effects of false starts and repetitions on the processing of subsequent words in spontaneous speech. Journal of Memory and Language, 34 (6), 709-738.

Fox Tree, J. (2007). Folk notion of um and uh, you know and like. Text a Talk, 27 (3), 297 -

314.

Fox Tree, J. (2010). Discourse markers across speakers and settings. Language and Linguistics Compass, 4 (5), 269-281.

Fuller, M., Masteller, V. \& Talkington, E. (2017). Circle Mirror Transformation: Play guide. Retrieved from

https://actorstheatre.org/wpcontent/uploads/2016/12/Circle-Mirror-

Goldman-Eisler F. (1951). The measurement of time sequences in conversational 
Behaviour. British Journal of Psychology, 42 (4), 355-362.

Goto, M., Itou, K. \& Hayamiza, S. (1999). A real-time filled pause detection system for spontaneous speech recognition. Proceedings of 6th European Conference, Speech Communication and Technology. Retrieved:

https://pdfs.semanticscholar.org

Krikke, T. (2014). Generation of fillers and grabbers in a natural dialogue system.

Retrieved from http://hmi.ewi.utwente.nl/verslagen/capita-selecta/CS-Krikke-

Teun.pdf

Labov, W. \& Fanshel, D. (1977). Therapeutic discourse. New York: Academic Press.

Maclay, H. , \& Osgood, C. E. (1959). Hesitation phenomena in English spontaneous speech.

Word, 15 (1), 19-44.

Mariano, S. (2002). A study of the translation of discourse markers in Italian Harry Potter

(Master Thesis). Retrieved from and the philosopher's Stone, by J. K. Rowling. https://www.swarthmore.edu/sites/default/files/assets/documents/linguistics/2002_marian o_sonia.pdf.

Marrouchi, Moez. (2019). Silence in Pinter's Silence and The Dumb Waiter. International Journal of Language and Literary Studies, 1 (3), 112-125.

Nicholson, H., Eberhard, K.\& Schuetz, M. (2010). Um ...I don't see any: The function of filled pauses and repairs. Proceedings of DiSS-LPSS Joint Workshop. (pp. 89-92). Tokyo, Japan.

O' Brein, S. (2006). Pauses as indicators of cognitive effort in post-editing machine Translation output. Across Language and Cultures, 7 (1), 1-21.

O' Connell, D. C. \& Kowal, S. (2004). The history of research on the filled pause as evidence of the written language bias in linguistics. Journal of Psycholinguistic Research, 33 (6), 459-474.

Oliveira, M. (2002) The role of pause occurrence and pause duration in the signaling o narrative structure. In: E. Ranchhod \& N. J. Mamede (Eds), Advances in natural language processing. Third International conference. Portugal.

Pribram, K. (1980). The place of pragmatics in the syntactic and semantic organization of language. In H. Dechert \& M. Raupach (Eds.), Temporal Variables in Current Speech: Studies in honour of Frieda Goldman-Eisler (pp. 13-19). The Hagu Mouton.

Richards, J. \& Schmidt, R. (2010). Longman dictionary of language teaching and applied linguistics (4th ed.). Britain: Pearson education limited.

Rose, R. (1998). The communicative value of filled pauses in spontaneous speech. (Master's thesis, University of Birmingham, United Kingdom).

Sacks, H., Schegloff, E., A. \& Jefferson, G. (1974). A simplest systematics for the organization of turn-taking for conversation. Language, 50 (4), 696-735.

Santos, N. M. \& Pablo, I. M. (2016). Fillers and development of oral strategic competence in foreign language learning. Porta Linguarum, 25,191-201.

Schachter, S., Christenfeld, N., Ravina, B., \& Bilous, F. (1991). Speech disfluency and the structure of knowledge. Journal of Personality and Social Psychology, 60 (3), 362- 
367.

Stenström, A. (2011). Pauses and hesitations. In K. Aijmer \& G. Anderson (Eds.), The

Handbook of Pragmatics: Pragmatics of Society (pp.538- 567). Berlin: Walter de Gruyter.

Stepanova, S. (2007). Some features of filled hesitation pauses in spontaneous Russian. Proceedings of the 16th ICPhS. Saarbrucken. Retrieved from http://citeseerx.ist.psu.edu/viewdoc/download;jsessionid=81AC7B325BA7456D7B0BE7 E904F5503A?doi=10.1.1.424.1420\&rep=rep1\&type=pdf

Swerts, M. (1998). Filled pauses as markers of discourse structure. Journal of Pragmatics, $30(4), 485-496$.

Tellier, M., Stam, G. \& Bigi, B. (2013). Gesturing while pausing in conversation: Self- oriented or partner-oriented? The combined Meeting of the 10th International Gesture Workshop and Speech in Interaction Conference. Tilburg. Retrieved from https://tiger.uvt.nl/pdf/papers/tellier.pdf

Tissi, B.( 2000). Silent pauses and disfluencies in simultaneous interpretation: A descriptive analysis. The Interpreters' Newsletter, 10, 103 -127.

Tsiaras, V., Panagiotakis, C. \& Stylianou, Y. (2009).Video and audio based detection of filled hesitation pauses in classroom lectures. 17th European Signal Processing Conference of Glasgow, Scotland.

Wang, B. \& Li, T. (2015). An empirical study of pauses in Chinese-English simultaneous interpreting. Perspectives, 23 (1), 124-142.

Weiling, M., Grieve. J., Bouma, G., Fruehwald, J., Goleman, J. \& Liberman, M. (2016). Variation and change in the use of hesitation markers in Language Dynamics and Change, $6(2), 199-234$.

Yuan, J., Xu, X., Lai, W. \& Liberman, M. (2016). Pauses and pause fillers in Mandarin monologue speech: The effects of sex and proficiency. The 8th Speech Prosody Conference. Boston. Retrieved from https://www.ldc.upenn.edu/sites/www.ldc.upenn.edu/files/speechprosody2016-pausesfillers-mandarin.pdf

Zellner, B. (1994). Pauses and the temporal structure of speech. In E. Keller (Ed.) Fundamentals of speech Synthesis and Speech Recognition (pp. 41-62). Chichester: John Wiley. 